\title{
'Act-as-if you are infected and infectious:' what has the global therapeutic community movement learnt from COVID-19?
}

\section{Introduction}

The new Coronavirus (COVID-19) has spread to nearly every country in the world since it first emerged in China at the beginning of the year (Newey and Gulland, 2020). More than 8.3 million people are known to be infected and more than 449, 000 deaths have been recorded - including 43,575 in the United Kingdom (UK) alone (ibid). The alcohol and drug treatment sector is an essential and highly valued element of our response to the risk presented by COVID-19 (HM Government, 2020), providing services for those who are at increased risk of becoming infected and/or infecting others (Matthews, 2019). The current public health crisis raises serious additional concerns for the well-being of people who use substances, ensuring service continuity, as well as the protection of those offering care and support on the front-line of service delivery (EMCDDA, 2020). Although a strategic priority of the World Health Organisation is to reduce mortality through appropriate care (WHO, 2020), little attention has been invested in the TC movement; how it has responded to adversity, evolved and diversified in a pandemic context. With this in mind, the purpose of this viewpoint paper is to begin a conversation about how TCs have begun to redefine and re-establish core treatment priorities while grappling with efforts to reduce harm and protect people from COVID-19.

\section{Main Discussion}

On the $25^{\text {th }}$ June 2020, the European Federation of Therapeutic Communities (EFTC) ${ }^{1}$ hosted a virtual COVID-19 learning event for practitioners from across the global TC movement. The aim of the event was to bring together TC professionals, from across the world, to reflect upon experiences, challenges and lessons from COVID-19, with a view to consider the future of TCs in both theory and practice. The event was attended by 40 members of the global TC community including but not limited to: Australia, America, Belgium, Czechia, Greece, Ireland, Italy, Spain, Turkey and United Kingdom. It was chaired by Karen Biggs (Chief Executive, Phoenix Futures, UK), who expressed a desire to 'understand the commonality of our experiences as a movement,' and opened by Phaedon Kaloterakis (President of EFTC, KETHEA, Greece) who gave a compelling and impassioned address to participants. During his opening speech, Phaedon called for the movement to become more political 'in the Aristotelian sense of the word in becoming concerned citizens'; contextualising and framing the event through the provision of five observations in light of the ongoing Coronavirus pandemic:

First, we need a stronger voice for treatment and TCs in particular so that... treatment becomes an integral part of the continuum of care of any national health system... and yes, this means more funding! Second, we have to advocate for services for the most vulnerable groups. Now! This is the time! Women, children, prisoners, refugees. Third, we should methodically design our efforts for integration; fighting the stigma - that is a constant battle - but also higher unemployment because the pandemic is bringing high unemployment. Fourthly, we should be more aware environmentally. We should educate ourselves, our staff, our members and then the public. Lastly, we should develop more efficient networks on a national level but also on an international level, reaching out to others even if... their views differ from our views. We need each other even more now!

The event consisted of two separate but interconnected sections: sharing our experiences and looking to the future, as well as an opportunity to ask questions. During the first section, four speakers - Anna Ollo

\footnotetext{
${ }^{1}$ The EFTC, established in 1981, is one of the largest recovery networks with members from over 70 organisations in 27 European countries, as well as associate members from Israel, Lebanon, Iran, Colombia, USA and Japan (EFTC, 2013). Members of the EFTC provide prison-based TCs, residential TCs, structured day programmes, peer led aftercare services and street-based advice services. As the EFTC recognises that TCs have been met with scepticism, it encourages self-evaluation amongst its members and active participation in research studies (EFTC, 2013).
} 
(Association Proyecto Hombre, Spain); Enrico Costa (CEIS Genova, Italy); Lyndsey Wilson-Hague (Phoenix Futures, United Kingdom) and Rod Mullen (Amity Foundation, United States of America) - were invited to share their experience of COVID-19 management, with a particular focus on infection control and programme delivery. The second section, led by Pauline McKeown (Coolmine, Ireland) and Karen Biggs (Phoenix Futures, United Kingdom), drew upon a series of key messages in and around how TCs had adapted to the needs and demands of a rapidly changing socio-political landscape, with a particular focus on what this means for the future of the TC movement in both the short and long term. The event was recorded and subject to thematic analysis by both authors of this comment piece. In doing so, five key themes emerged including, but not limited to: shelter; creativity; reintegration and employment; technology; and TC roots. Although these themes are presented here as discrete elements of the overall seminar, they were not only common to most of the presentations but, in many cases, overlapped with each other. Thus, creating safe shelter clearly resulted in a greater, more involved presence of re-entry residents and recent graduates in the day-to-day life of the 'home' community; both strengthening the role-model elements of that community and reassuring the returnees of their intrinsic value and worth during a time of uncertainty. All speakers involved in the event demonstrated a considered, pro-active response to COVID-19. What was very noticeable across all participants input, was the presence and recognition of early awareness, with services either preparing for lockdown or beginning lockdown processes before officially instigated by their respective governments.

January to March, we did a lot of monitoring... around the world... and realised that we were pretty much on our own to deal with this situation. So in March as we got our first cases in the US, we shut down campus movement immediately because we realised that the real risk was people coming in and out of the community.

(Rod Mullen, USA)

Even before government directed restrictions came into effect, we took steps to ensure community involvement by engaging with the peer community to implement their own guidelines. The community set themselves various rules which included: no hugging, keeping a social distance, increased cleaning regimes, a reduction in group sizes and no non-essential visitors which sadly included families.

(Lyndsey Wilson-Hague, UK)

Others talked about gathering their whole community together to discuss the coming storm and seek community-led solutions to the changes which were about to upend existing practices.

What is coming through is messages around the strength of the community and the responsibility we have to take control ourselves if others around us are not taking control.

(Anna Ollo, Spain)

Our graduates and our after-care clients instantly created structure for themselves. They instantly stood up and took personal responsibility. So in terms of being able to meet socially distancing, being able to check in with each other. They really took a very strong personal ownership around that... Right now we're calling it an organic peer after-care structure.

(Pauline McKeown, Ireland)

Our clients took massive personal responsibility... they instantly got with this and took significant personal responsibility and staff too in supporting them to do that. 
These quotations graphically illustrate a longstanding, almost universal, feature of the TC treatment milieu: consisting of a dynamic balance between the creation of a safe, supportive, loving community and a challenging and demanding environment where new behaviours can be practiced (Goethals et al, 2011). From the beginning of the pandemic, representatives described occurrences consistent with the former element as TCs became 'shelters from the storm'. Indeed, a number of TCs reported that the pandemic had resulted in increased treatment requests, as 'living out there' in the wider community became increasingly hazardous. In most cases, TCs reported that these changes had begun before formal Governmental guidance and instruction and crucially, had been a collective process. The aforementioned endeavours epitomise two unique characteristics of a TC: the recognition that all community members are valuable sources of information and support and prioritisation of a highly-structured, self-reliant programme (Center for Substance Abuse Treatment, 1999).

The hierarchical structures within the therapeutic communities worked well during Covid... the smaller groups, working in the environment, working in a maintenance role... the actual operation of the TC worked well.

(Pauline McKeown, Ireland)

TCs have always been a crucible of creativity and new ideas. Early TC practices were littered with experimentation in psychodrama, drama-therapy and music and throughout their 50 year history, they have consistently proved to be adaptable and adventurous (Bratter et al, 1985; Rawlings and Yates, 2001). One presenter described this as adaptation, capacity and capability when explaining how their TC had introduced a preliminary admission stage for new residents where they could be kept safely in isolation until it was safe to physically integrate them into the main TC community. Most presenters noted inventive and original responses to lockdown measures and the pandemic: from TCs adapting the day-to-day structure of the community to facilitate social distancing measures ('we say physical distancing with social intimacy,' Mullen); to rearranging and reallocating physical space to allow a continued service; to making their own face masks; sourcing their own equipment and perhaps most memorably, to establishing a community handwashing bell routine.

We got a big bell and we ring that bell five times a day! And everybody goes and washes their hands. Because we realised that we have to establish new habits!

(Rod Mullen, USA)

We feel we have embraced the community as method approach now more than ever (...) there is now more community-led initiatives such as community led seminars (...) and senior residents have shown incredible resilience and support to staff and other community members, they now support the formulation of weekly timetables.

(Lyndsey Wilson-Hague, UK)

Interestingly a number of presenters referred to new developments in their service which were, in fact, at once ritualistic, celebratory and intrinsically rooted in self-help ideology. One presenter mentioned an increase in the use of resident-taught seminars which was once a central element of TC practice that has been marginalised in some communities in recent years. It was particularly interesting to listen to 
presenters utilise longstanding TC terminology and concepts to reinforce key pandemic messages: 'act-as-if you are infected and infectious' and 'the health of my brother depends on my behaviour and his behaviour can have an impact on my health.' Drawing on core treatment principles, suggests an almost 'back to basics' approach to treatment whereby the core deliverables were revisited and reinstated to ensure residents were still able to participate in TC life. Although lockdown presented opportunities for services to draw upon the TC community itself to find courage, strength and responsivity through adversity, the collateral consequences of the pandemic were, at times, palpable. Presenters discussed concerns for the TC movement on both a micro, individual level and macro, structural level. There was a concern that the individual's opportunity to (re)integrate into the wider community and build positive relationships with friends and family were significantly reduced given that trips to the local community were stopped as were social visits. It was pointed out by some speakers that most TC graduates and re-entry members faced continued stigma and certain professions were (probably permanently) closed to them with those jobs to which they could aspire being generally hardest hit by the virus and the associated lockdown.

The lockdown was a critical period for persons with substance use disorders as [it] could result in relapse processes due to their emotional management difficulties.

(Anna Ollo, Spain)

Also a major concern for us was the economic impact of the pandemic because half of the persons on our treatment programmes do not have a job and those who find one, it's usually an unqualified job which makes them more vulnerable in crisis situations.

(Anna Ollo, Spain)

For those in the re-entry or social reintegration phase of their programme, the lockdown was extremely difficult and a number of presenters noted the feelings of loneliness and frustration which impacted upon this group. The solution in most of the TCs reviewed was one which suited both their needs and the needs of those at an earlier stage in their TC journey. Re-entry residents and recent graduates became increasingly involved back in the 'home' community as volunteers and adjunct staff members.

The pandemic posed huge health risks for those with addiction problems, especially due to their high level of mental and physical comorbidity that affects many of them.

(Anna Ollo, Spain)

In addition, it became apparent that services were dealing with increased fear, anxiety and indeed grief amongst all community members; staff and residents alike.

There was a real fear that what was going on in the world around them would drive people away from support when they needed it the most, so we knew staff would be extremely important keeping people in the service but we also knew that staff had their own fears.

(Lyndsey Wilson-Hague, UK)

We had a lot of grief and people wanted to go home to see their families and we had to tell them that they couldn't come back not just for their own safety but the community's safety.

(Rod Mullen, UK) 
Some TCs have been using some elements of technology with clients for some time (eg. TCs using text messages to maintain contact with residents on weekend leave) but this has accelerated due to the virus and it was clear that some of these changes will remain in place in the post-pandemic period.

Partner agencies and graduates have also been supporting the communities by delivering a range of interventions online which we can stream directly into the services: such as keeping fit and creative writing, mindfulness and gender-specific support.

(Lyndsey Wilson-Hague, UK)

So thanks to this, the association has a chance to evolve and we were able to see the possibilities that technologies can offer. So part of the changes that we implemented during the lockdown period will still be in place: such as the telematic attention.

(Anna Ollo, Spain)

What was perhaps the most significant emergent theme from the seminar was an almost atavistic and instinctive return to the earlier bones of the TC idea. The roots of the TC lie in an ethos of humanist collectivism. Historically, what marked out the TC from other treatment interventions was the absence of a staff/client divide. With the increasing professionalisation of the movement over the years, this distinction has become blurred (Yates, 2011). But during the pandemic, there appears to have been an increased element of staff and residents facing the same issues and responding as a whole community (sheltered from both the virus and the outside world) and taking decisions and responding to the threat collectively. Indeed, there was an expectation that staff would behave more like re-entry residents than professional staff.

As these rules came from the communities themselves, there was 'buy-in' from the start.

(Lyndsey Wilson-Hague, UK)

Reducing group times in order to free up staff to be more visible and to connect with the community on the floor.

(Lyndsey Wilson-Hague, UK)

We too increased our staffing presence and we've had a lot of redeployment internally... We're looking at associate staff. We're looking at graduates having a stronger presence [in the TC]

(Pauline McKeown, Ireland)

So it would seem that the pandemic has in some ways encouraged a return to an earlier form of TC, of a community together responding to the external world together.

The strength has been the sense of community (...) the sense of community has pushed all the guests to understand that the health of my brother depends on my behaviour and his behaviour has an impact upon my health. 
This, of course is the absolute essence of the TC approach.

\section{Conclusion}

Overall, the event provided a clear perspective on how the TCs' protective factors become both clearer and more critical in times of crisis with the ability to 'cocoon' people who are most vulnerable. The protective factors of residential settings have been highlighted by recent announcements by the Welsh Government (2020) outlining plans to build a residential facility for low risk female offenders as a diversion from custody as well as the Scottish Government releasing further funding of $£ 150,000$ for residential beds for newly released prisoners (Freeman, 2020). What was noticeable too was the ability of TCs to adapt and utilise the notion of community-as-method in a way that heightens its importance as a mechanism to allow services to evolve in times of crisis by looking to the past and re-establishing traditional TC treatment principles.

The current pandemic and its impact throws into sharp focus two important stages of residential treatment: pre and post treatment. In most TCs, the induction of new members had at least slowed; most often for practical reasons around infection control. A number of presenters noted that they had responded to this by enhancing pre-entry procedures; often using technological and virtual aids. It seems both likely and appropriate that these additional interventions are re-examined and built upon in the postpandemic period. Likewise, the lockdown process highlighted the vulnerability of those in after-care settings. Again, technology might provide some solutions here but in both pre-entry and after-care there will be questions to be resolved around the security of digital platforms and the digital 'literacy' of those involved.

What seems clear is that drug-free therapeutic communities have coped well with the problems which have arisen as a result of the current pandemic. However, it should be acknowledged that in the majority of cases, they have done so from a starting position of reduced and/or limited funding and marginalisation of their work. If the pandemic has proved one thing, it must be the essential nature of the work in which drug-free TCs are involved. That said, it seems highly likely that the post-pandemic period will be marked by high levels of unemployment and reduced funding for public services.

We were struggling before (...) there is already an economic impact of the pandemic and the government's reaction to that is going to be critical.

(Karen Biggs, UK)

\section{Reference List}

Bratter, T., Collabolleta, E., Fossbender, A., Pennachia, M. \& Rubel, J. (1985) 'The American self-help residential therapeutic community: A pragmatic treatment approach for addicted character-disordered individuals' in Bratter, T. and Forrest, G. (eds.) Alcoholism and Substance Abuse: Strategies for clinical intervention. London: Free Press. Pp. 461-507.

Centre for Substance Abuse Treatment. Treatment of Adolescents with Substance Use Disorders. Rockville: Substance Abuse and Mental Health Services Administration. Available on-line at: https://www.ncbi.nlm.nih.gov/books/NBK64342/ [available on-line at: 07.08.2020]

European Federation of Therapeutic Communities. (2013). An Overview. Available on-line at: https://eftc.ngo/organisation/\#overview [accessed 13.07.2020]. 
European Monitoring Centre for Drugs and Drug Addiction (2020) COVID-19 and people who use drugs. Available on-line at: https://www.emcdda.europa.eu/publications/topic-overviews/covid-19-and-peoplewho-use-drugs en [accessed on 30.06.2020]

Freeman, J. (2020) Coronavirus (COVID-19) update Health Secretary's speech 3 May 2020. Available on-line at: https://www.gov.scot/publications/coronavirus-covid-19-update-health-secretary-speech-03-2020/ [accessed on 14.07.2020

Goethals, I, Yates, R., Vandervelde, S., Broekaert, E. and Soyez, V. (2011) A religion too far: on the hidden ideology of a social therapeutic belief system, Mental Health and Substance Use, 4(3), 177-194.

HM Government (2020) COVID-19: guidance for commissioners and providers of services for people who use drugs or alcohol. Available on-line at: https://www.gov.uk/government/publications/covid-19guidance-for-commissioners-and-providers-of-services-for-people-who-use-drugs-or-alcohol/covid-19guidance-for-commissioners-and-providers-of-services-for-people-who-use-drugs-or-alcohol [accessed on 30.06.2020]

Matthews, L. (2019) 'Stay safe' in Drink and Drug News. COVID-19: The outbreak that changed everything. April 2020. Available on-line at: https://view.joomag.com/drink-and-drugs-news-ddn-april-2020$1 / 0620351001586166834$ ?short\& [accessed on 30.06.2020]

Newey, S. and Gulland, A. (2020) What is Coronavirus, how did it start and how big could it get? The Telegraph. Available on-line at: https://www.telegraph.co.uk/news/2020/06/30/what-covid-19-pandemicspread-uk-coronavirus/ [accessed on 30.06.2020]

Rawlings, B., \& Yates, R. (2001). Fallen angel: an introduction. In B. Rawlings \& R. Yates (eds.), Therapeutic communities for the treatment of drug users. London: Jessica Kingsley. Pp. 9-25

Welsh Government (2020) Female offenders to get residential centre in Wales. Available on-line at: https://media.service.gov.wales/news/female-offenders-to-get-residential-centre-in-wales [accessed on 14.07.2020]

WHO (2020) COVID-19 Strategy Update. Available on-line at: file:///C:/Users/sschgosl/Downloads/covidstrategy-update-14april2020.pdf [accessed on 30.06.2020]

Yates, R. (2011) Therapeutic communities: can do thinking for must have recovery, Journal of Groups in Addiction and Recovery, 6(1/2). Pp. 101-116. 